\title{
Eating habits and attitudes and their relationship with Body Mass Index (BMI)
}

\author{
Ana Rodríguez Santamaría* \\ Isaac Amigo Vázquez** \\ Dolores Paz Caballero** \\ Concepción Fernández Rodríguez**
}

* Clinical Psychologist. Servicio de Salud del Principado de Asturias

** Psychology Departament. Oviedo University

SPAIN

\begin{abstract}
Background and Objectives: To study the differences in eating attitudes and habits between subjects of normal weight and subjects who are overweight and to analyze in each group the relationship between these habits and attitudes and BMI, taking gender as a modulating variable.

Methods: A total of 191 subjects, 117 women and 74 men, took part in this study. 102 subjects made up the overweight/obesity group and 82 subjects made up the control group. All of them were given a questionnaire comprising 26 items (EAT 26 Eating Attitudes Test) plus an additional group of 10 extra items.

Results: The overweight group shows a significantly higher score in mood-related ingestion than the group with normal weight. Subsequent analyses indicate that while in the overweight/obesity group there is a positive correlation between the oral control scale and $\mathrm{BMI}$, in the normal weight control group there is a negative correlation between oral control and BMI. Amongst the women in the overweight group a significant relationship was observed between skipping meals, oral control and BMI. $50.7 \%$ of the dieters stated that their attempts to lose weight had generally been followed by an even greater weight increase. Furthermore, $88.5 \%$ of the dieters stated that they had been unable to maintain the weight loss in the long term.

Conclusions: The results indicate that the same restrictive practices can have different effects depending on the BMI and the sex of the subjects.
\end{abstract}

Received: 11 November 2008

Revised: 9 June 2009

Accepted: 30 July 2009 


\section{Introduction}

There exists at present enormous concern amongst the population of the developed world regarding being overweight and obesity. This concern is generally justified by alleging health motives. The deeper motivation is, however, to a considerable extent, aesthetic. It is a slim body that is considered an attractive body in our society, amongst other things because, in a context of nutritional overabundance, it is more and more difficult to maintain a normal weight ${ }^{1}$. In this cultural context all kinds of strategies to lose weight have flourished: hypocaloric diets, restrictive eating habits, nutritional compounds, pharmaceutical products and such extreme measures as skipping certain meals. Thus, we find ourselves in the situation where more than $70 \%$ of the population of the western world admits that they are attempting either to lose weight or to maintain their present weight ${ }^{2,3}$.

However, despite all these attempts to lose weight, figures show that the prevalence of obesity and being overweight has grown continually and alarmingly since the eighties ${ }^{4,5}$. All of this would lead one to suspect that, although for many these strategies may be of use in the short term, this is not the case in the long term. Several studies seem to show this. Half of the people tend to give up hypocaloric diets within two months of starting them ${ }^{6}$. Furthermore, $95 \%$ of people tend to recover their initial weight between one and five years after finishing the diet ${ }^{7}$. Similarly, it has been observed that some subjects may gain a surplus of additional weight with respect to their weight before the diet. Recent prospective studies ${ }^{8,9}$ show that attempts to lose weight seem to be associated in some subjects with a subsequent greater increase in weight (equal to or greater than $2 \mathrm{~kg}$ ). Finally, weight and food can be the cause of great worry in some people ${ }^{10,11}$.
The theory of food ingestion restriction is one theory which has been put forward to explain the organism's lack of response to restrictive diets, which limit the number of calories consumed per day ${ }^{12}$. According to this theory, efforts to restrict ingestion of food can lead to eating less or, paradoxically, to eating considerably more. The clearest illustration of this effect is a classic experiment. A group of subjects are given a previous sample of a very high-calorie substance (e.g. a milk shake) or a sample of a very lowcalorie substance (e.g. water). The people are then asked to take part in a test where they are left alone to put a series of foodstuffs in order according to which they preferred. They can eat as much as they want. The results of this line of investigation show that the subjects who had been on a diet just before the tasting test ate more during the test if the food they were given previous to the test was high in calories, whilst those who had not been on a diet exhibited compensatory regulating behavior and ate less following a previous highcalorie intake. All of this underlines the role of restrictive diets in disinhibited eating conducts $^{13}$. A similar response has also been observed in laboratory animals ${ }^{14,15}$.

This paradigm is tremendously important to explain the eating behavior of people who go on diets. That is to say, although these people eat less at times, the continual restriction of their food ingestion also leads them, on many occasions, to eat more ${ }^{16}$. Breaking the diet and consuming a high-calorie food can lead to uncontrolled consumption of food, generally high in calories. However, it is also possible for other stimuli to trigger off this uncontrolled eating and amongst these are the following: a depressed mood, the belief that one has consumed a very high-calorie food, the need to evade the weight problem itself, giving up smoking or the tasting of foods. 


\section{Method}

The aim of the research is to study the relationship between eating attitudes and habits and BMI and for this purpose two groups were used. One group consisted of people who were overweight/obese and who attended a clinic specializing in nutrition, as it is here that it is possible to obtain a sample of people who are overweight/obese to differing degrees and who are making an effort to lose weight. The control group was made up of people whose weight was normal. These people were recruited in a primary care centre.

Given that concern about the body is greater in women than in men, the modulating effect of gender as a modulating variable will be analyzed. Similarly, there exist many data which indicate the close relationship which exists between educational level and $\mathrm{BMI}^{17,18}$. For this reason, the influence of this variable was tested in the analyses carried out.

In order to measure attitudes, the EAT-26 was used ${ }^{19}$. This is an abbreviated questionnaire derived from the original EAT-40 "Eating Attitudes Test". It is used in both the normal and clinical population. It has been repeatedly revalidated and is used to evaluate three factors: Dieting, Food Preoccupation/Bulimia and Oral Control ${ }^{19,} 20$. Apart from the EAT, the subjects were given a 10-item questionnaire referring to eating behavior not included in the EAT.

\section{Participants}

A total of 191 subjects participated in this study. 117 were women and 74 were men of ages between 15 and 65 . The participants in the control group, whose BMI was between 21.3 and 26.9 , were recruited in primary care clinics. The subjects who were overweight or suffered obesity had a BMI of between 27 and 57.2 and were recruited in the specialized nutrition clinics of the Central University Hospital of Asturias and the "Virgen Blanca" Hospital of León. The control group was made up of 82 subjects (36 men and 46 women) of between 20 and 80 years of age (mean age $=40.78)$ and with a mean BMI of 24.65. The overweight group comprised 109 subjects (38 men and 71 women) of between 15 and 80 years of age (mean age $=43.14$ ) and with a mean BMI of 34.23. In order to participate in this study, the subjects had to give their written consent. In the case of the minors, it was the parents who had to sign the consent form.

The exclusion criteria were: diagnosis of pathologies which could directly affect BMI (diabetes), consumption of specific pharmacological treatments for obesity, consumption of medication which could have a direct effect on BMI (antidepressants). A previous record of treatment in the Nutrition Clinic was used to rule out those subjects who fulfilled any of the abovementioned exclusion criteria. In total, 11 subjects were excluded from the study because they suffered from type II diabetes and 16 because they were taking antidepressants. Three subjects (two women and one man) refused to take part when they were told that, after the interview, they were to be measured and weighed.

\section{Material}

The compilation of data was carried out using information offered by the patients themselves and from reading their clinical records. A questionnaire comprising 26 items was used (EAT-26, Eating Attitudes Test), together with an additional group of 10 extra items, and an interview to obtain sociodemographic and clinical data. 
In our study, the EAT- $26^{19}$ was used as it is the method which has been most frequently validated as a means for evaluating dieting and restrictive behavior conducts and also other habits such as bingeing and preoccupation with food. Amongst the Spanish population it has been validated by ${ }^{20}$ (validity coefficient of 0.61 ).

The EAT makes it possible to obtain scores on three scales:

1. Dieting: This refers to the tendency to avoid certain types of food and to be concerned about physical appearance.

2. Food Preoccupation/bulimia: This refers to the tendency to be constantly thinking about food and to exhibit behavior associated with bulimia (bingeing and purging).

3. Oral Control: This refers to the tendency towards self-control with regard to food and perceived social pressure to control one's weight.

As well as the EAT, the subjects were given a 10-item questionnaire with a view to evaluating firstly, what we have called "extreme measures to avoid gaining weight or to lose it". These included items 27 (skipping main meals), 28 (consuming substances to avoid being hungry), 29 (use of diuretics) and 30 (use of laxatives). The following were also evaluated: mood-related ingestion (item 31); ingestion provoked by seeing food (items 36 and 38); eating meals in front of the television (item 34); night time ingestion (item 37) and eating meals standing up (item 35). Subjects answered the items in the EAT and those in the questionnaire using a scale of frequency from 1 to 6 points.

In addition, two questions were included in the form which were only asked to those participants who, in the interview, had previously acknowledged having been on a diet in the past. Item 32 "Have you observed that after finishing a diet you gain more weight and so end up weighing more than when you started?" The aim of this was to study what we have called the rebound plus effect of dieting. Item 33 "After going on a diet, have you been able to maintain the weight loss until now?" The aim of this question was to observe the efficiency of the diets which the subjects of our sample had carried out with regard to weight loss and the maintaining of weight loss.

\section{Procedure}

In the interview, carried out before the patient entered the doctor's practice, each patient was told what the tests included in this study would consist of and was asked to give written consent. Subsequently, data regarding age, educational level and past and present diets was compiled and finally the subjects were measured and weighed. Weight and height were measured without shoes and with the minimum amount of clothing in order to obtain the most accurate measurements possible.

Each subject was given an explanation regarding how to answer the questionnaire and the alternative answers given in the EAT-26 and the 10 additional items used in this study. The subjects filled in the questionnaire before entering the primary care or specialist clinic. Once the subjects had finished answering these questions, some of them were also asked questions about use and efficiency of the diets.

\section{Data Analysis}

For the statistical processing, the SPSS/PC+ version 15.0 was used. The comparison between the control group and the overweight 
group with regard to attitudes and eating habits was carried out using the Multivariate Analysis of the Variance (MANOVA) technique. Bivariate correlations were calculated in each of the groups in order to analyze the relationship between weight and eating attitudes and habits (the 3 subscales of the EAT-26 and the 10-item questionnaire referring to eating behavior). The possible modulating influence of gender was analyzed.

\section{Results}

\section{Descriptive analysis of the samples}

The distribution of BMI in each of the samples can be seen in table 1 . No differences were observed between the two samples with regard to gender (chi-square ${ }_{(1)}=1.61, \mathrm{p}=0.204$ ) nor with regard to age $\left(\mathrm{t}_{(189)}=-1.16, \mathrm{p}=0.246\right)$. With regard to educational level, there were significant differences between the two groups (Chi-square $\left._{(2)}=55.31, \mathrm{p}<0.001\right)$, with predominance of subjects with higher education studies in the normal weight group and of subjects with primary studies in the overweight group.

\section{Use of diets}

Of the 191 subjects which make up the total sample, 45 deny ever having dieted whereas 55 subjects in the control group $(67 \%)$ and 91 in the overweight/obesity group $(84.3 \%)$ say they have dieted in the past. Within the group of men, 47 say they have dieted in the past and 27 that they have not. In the group of women, 101 had dieted and 16 had not.

With regard to the efficiency of the diets in the long term, $88.5 \%$ of the participants who had dieted said that the diet had not been efficient in maintaining the weight loss until the present. $11.5 \%$ said that the diet had worked and they had more or less maintained the weight loss until the present.

In relation to the "rebound plus" effect of the diets, $50.7 \%$ of the participants who had dieted said that after the diet their weight increased. On the other hand, $49.3 \%$ were not aware of such an increase.

Differences between the two samples regarding attitudes and eating habits.

The MANOVA which was carried out showed significant differences between the two groups with regard to attitudes and eating habits as a whole $\left(\mathrm{F}_{(13,154)}=2.182, \mathrm{p}=0.013\right)$. These differences disappeared, however, when the effect of educational level was taken into account by introducing it as a covariate in the analysis $\left(\mathrm{F}_{(13,153)}=1.181, \mathrm{p}=0.298\right)$. In this case, as can be seen in table 2 , the only variable to be significantly different between the two groups was the mood-related ingestion variable, which was more common in subjects belonging to the overweight group. In order to analyze those differences in BMI not attributable to educational level, this variable was controlled statistically when carrying out the analyses.

Relationship between BMI and the rest of the variables (gender, age and attitudes and eating habits) in each of the samples.

No differences were observed between the BMI of men and that of women within each sample $\left(\mathrm{t}_{(80)}=0.93, \mathrm{p}=0.353 ; \mathrm{t}_{(107)}=-1.34\right.$, $\mathrm{p}=0.181$, for the control group and overweight group respectively), nor was there any correlation between BMI and age $(r=0.215$, $\mathrm{p}=0.053 ; \mathrm{r}=-0.02, \mathrm{p}=0.839$ ), although, as can be seen, in the control group the positive relationship between BMI and age was close to being statistically significant. With re- 
Table 1

Descriptive analyses of the samples

\begin{tabular}{lclcl} 
& BMI & Gender & Mean age & Educational level \\
\hline Control sample $(\mathrm{N}=82)$ & $21.3-26.9$ & $\begin{array}{l}\text { Male }=36 \\
\text { Female }=46\end{array}$ & 40.78 & $\begin{array}{l}\text { Primary }=11 \\
\text { Secondary }=15 \\
\text { Higher }=56\end{array}$ \\
\hline Overweight sample $(\mathrm{N}=109)$ & $27-57.2$ & $\begin{array}{l}\text { Male }=38 \\
\text { Female }=71\end{array}$ & \multirow{2}{*}{43.14} & $\begin{array}{l}\text { Primary }=66 \\
\text { Secondary }=23 \\
\text { Higher }=20\end{array}$ \\
\hline
\end{tabular}

gard to educational level, the differences in BMI between the three educational levels were only significant in the overweight group $\left(\mathrm{F}_{(2,106)}=20.412, \mathrm{p}<0.001\right)$, where a clear inverse relationship was observed between the two variables.

The relationships between BMI and attitudes and eating habits in each of the groups are shown in table 3 . Bearing in mind the significant differences between the groups with regard to educational level and the relationship of this variable with BMI in the overweight group, the influence of the educational level has been removed in these correlations. In the control group, the only variable related to $\mathrm{BMI}$ is the oral control scale $(r=-0.399, p<0.001)$.

In the overweight group, the variables related to BMI are the use of diuretics $(r=0.22$, $\mathrm{p}=0.013)$ and laxatives $(\mathrm{r}=0.23, \mathrm{p}=0.010)$, and also the oral control scale $(\mathrm{r}=0.29, \mathrm{p}=$ 0.002). When the correlation coefficients obtained in each group were compared, statistically significant differences were observed in the oral control scale $(Z=-4.74$, $\mathrm{p}<0.001)$. Thus, although this variable had a high negative correlation with BMI in the control group, it had a positive and significant relationship with BMI in the overweight subjects.
Differences within each sample between men and women regarding attitudes and eating habits and how these are related to BMI.

When men and women were compared regarding attitudes and eating habits, certain differences were found. In the control group there were gender-related differences in mood-related ingestion $\left(\mathrm{F}_{(1,72)}=5.954, \mathrm{p}=\right.$ 0.017 ), where the highest scores corresponded to women. In the group of overweight subjects, the women also had higher scores for mood-related ingestion $\left(\mathrm{F}_{(1,90)}=\right.$ $5.43, \mathrm{p}=0.022$ ) whilst the habit of getting up during the night to eat was more frequent amongst the men $\left(F_{(1,90)}=-9.83, \mathrm{p}=0.002\right)$. In all cases the effect of the educational level was taken into account by introducing it as a covariate in the analysis.

The correlations with BMI for men and women within each group (see table 4) were also slightly different.

In the control group, the negative relationship between oral control and BMI existed both in men and women, whilst mood-related ingestion showed a positive relationship with BMI in the men. In the overweight group, skipping meals, taking diuretics and laxatives and the score on the oral control scale could be directly associated with BMI, but only in the group of women. 
Table 2

Differences found in MANOVA comparing groups in attitudes and eating habits. Educational level has been used as covariate

\begin{tabular}{lll} 
& $\mathrm{F}_{(1,166)}$ & $\mathrm{Sig}$ \\
\hline DIETING SCALE & 3.126 & $0.079 \dagger$ \\
FOOD PREOCUPATION/ BULIMIA SCALE & 3.233 & $0.074 \dagger$ \\
ORAL CONTROL SCALE & 0.007 & 0.934 \\
Skipping meals & 0.300 & $0.585 \dagger$ \\
Consumption of pills to prevent sensation of hunger & 0.005 & 0.945 \\
Consumption of diuretics & 0.754 & 0.386 \\
Consumption of laxatives & 1.224 & 0.270 \\
Mood-related eating & 9.001 & $0.003 * *$ \\
Eating in front of the television & 1.660 & 0.199 \\
Eating meals standing up & 0.723 & 0.397 \\
Eating despite feeling full & 1.436 & 0.232 \\
Getting up at night to eat & 1.950 & 0.164 \\
Eating when seeing food available & 0.590 & 0.443 \\
\hline
\end{tabular}

$* *: \mathrm{p}<0.01$

$\dagger$ Significant differences before removing the effect of level of studies.

Table 3

Partial correlations between BMI and attitudes and eating habits in each of the groups removing the effect of the educational level

\begin{tabular}{lcc} 
& $\begin{array}{c}\text { Control group } \\
(\mathrm{N}=82)\end{array}$ & $\begin{array}{c}\text { Overweight group } \\
(\mathrm{N}=109)\end{array}$ \\
\hline Skipping meals & -0.151 & $0.145 \dagger$ \\
Consumption of pills to prevent sensation of hunger & 0.041 & -0.008 \\
Consumption of diuretics & 0.128 & $0.249^{*} \dagger$ \\
Consumption of laxatives & 0.081 & $0.217^{*} \dagger$ \\
Mood-related eating & $0.192 \dagger$ & -0.096 \\
Eating in front of the television & -0.062 & -0.126 \\
Eating meals standing up & 0.017 & -0.090 \\
Eating despite feeling full & 0.081 & 0.078 \\
Getting up at night to eat & 0.017 & -0.167 \\
Eating when seeing food available & 0.031 & -0.017 \\
DIETING SCALE & -0.138 & $0.027 \dagger$ \\
FOOD PREOCCUPATION SCALE & -0.101 & 0.028 \\
ORAL CONTROL SCALE & $-0.399^{* *}$ & $0.216^{*}$ \\
\hline
\end{tabular}

$*: \mathrm{p}<0.05 ; * * \mathrm{p}<0.01$

$\dagger$ : significant correlation before removing the influence of educational level. 
Table 4

Correlations between BMI and attitudes and eating habits in men and women, taking into account the effect of the educational level

\begin{tabular}{lcccc} 
& \multicolumn{2}{c}{ Control Group } & \multicolumn{2}{c}{ Overweight Group } \\
\hline $\mathrm{S}$ & Male $(\mathrm{N}=36)$ & Female $(\mathrm{N}=46)$ & Male $(\mathrm{N}=38)$ & Female $(\mathrm{N}=71)$ \\
\hline Skipping meals & 0.041 & $-0.236 \dagger$ & -0.272 & $0.346^{* * \dagger}$ \\
Consumption of pills to prevent & -0.185 & 0.172 & -0.180 & 0.091 \\
sensation of hunger & & & & \\
Consumption of diuretics & 0.087 & 0.148 & -0.239 & $0.367^{* * \dagger}$ \\
Consumption of laxatives & 0.254 & -0.101 & 0.096 & $0.251^{* \dagger}$ \\
Mood-related eating & $0.287^{* \dagger}$ & 0.123 & -0.230 & -0.057 \\
Eating in front of the television & 0.032 & 0.013 & -0.019 & -0.176 \\
Eating meals standing up & 0.000 & -0.020 & -0.252 & -0.010 \\
Eating despite feeling full & 0.063 & -0.161 & 0.077 & 0.055 \\
Getting up at night to eat & -0.058 & 0.016 & -0.201 & -0.110 \\
Eating when seeing food available & -0.107 & 0.146 & 0.036 & -0.030 \\
DIETING SCALE & 0.027 & -0.199 & -0.039 & $0.049 \dagger$ \\
FOOD PREOCCUPATION SCALE & -0.160 & 0.025 & -0.181 & 0.025 \\
ORAL CONTROL SCALE & $-0.460^{* * \dagger}$ & $-0.300^{* \dagger}$ & -0.040 & $0.326^{* *}$ \\
\hline
\end{tabular}

$*: \mathrm{p}<0.05 ; * *: \mathrm{p}<0.01$

$\dagger$ : significant correlation before removing the influence of educational level.

\section{Discussion}

The results of this study show how the same eating attitude can have opposite effects in subjects whose weight is normal and those who are overweight. More specifically, a higher score on the oral control scale would appear to make it easier for normal weight subjects to control their weight whilst a high score on the same scale is related to a higher BMI in subjects in the overweight group, particularly in women. A close relationship was also observed between people's educational level and their BMI. In particular, people with a lower educational level are also those with a higher BMI. This relationship is one which appears repeatedly in the literature $^{17,18}$ and shows that this variable has a decisive influence on any comparison made between overweight and normal weight sub- jects. In this study we were interested in knowing what part of the differences in BMI might be linked to educational level. With regard to this, the data indicates that the differences found in the "dieting", "food preoccupation/bulimia" and "skipping meals" variables disappear when the educational level of the sample is removed.

It may seem a contradiction that "oral control", which implies not eating meals when hungry and controlling the amount eaten during meals, should be associated with a high BMI. It would appear, however, that in some subjects this attempt to control eating habits frequently fails and is correlated with conducts of lack of control and behavioral patterns which in the long term can lead to their initial weight surplus being maintained or even to it increasing. In fact, in the women in the overweight group, a 
significant relationship was observed between skipping meals and BMI. This type of behavior tends to lead to a subsequent compensatory ingestion of food, characterized by a certain lack of control and during which a far higher number of calories are consumed than in a normal meal ${ }^{21-23}$.

Whilst a positive correlation was found between skipping meals and oral control in general and BMI in the overweight women, a negative correlation was observed between oral control and BMI for women in the control group. These results may appear to contradict the above-mentioned restriction theory. However, it is important to bear in mind that one of the limits of this theory ${ }^{13}$ is that it cannot explain why some people are capable of restricting their ingestion of food (e.g. restrictive anorexics) and at the same time losing weight. The results of this study indicate that overweight women are less likely to lose weight when they restrict their food ingestion than normal weight women, in whom restrictive maneuvers appear to be associated with a lower BMI.

The results also showed that the only variable which significantly differentiates the normal weight group from the overweight group is mood-related ingestion. That is to say, people who are overweight use food as a strategy to help them to face emotional states. Furthermore, this variable also related positively to BMI in the men in the normal weight group. These conclusions had already been obtained in previous stud$\mathrm{ies}^{24}$. Resorting to ingestion as a way of controlling emotional problems results in the person being caught up in a vicious circle from which it is then very difficult to escape. The ingestion of food is a successful way of coping in the short term, in the sense that it raises the spirits and decreases the anxiety triggered off by food ingestion restriction conducts or caused by other fac- tors. However, what is a possibly useful response in the short term can become a dysfunctional habit for managing depressive states which leads to a gaining of weight in the long term. These results appear consistent with the theory of food ingestion restriction $^{25}$, given that, as this theory predicts, negative emotional states could be leading some subjects to eat more in the long term. Finally, the consumption of substances to avoid feeling hungry, the use of diuretics and the use of laxatives has been associated with a high $\mathrm{BMI}^{26}$, as has also been observed in this study.

With regard to the long term effects of dieting, we have observed that $88.5 \%$ of subjects maintain that their diets have failed with regard to long term consolidation of weight loss. These figures are similar to the results of other studies which report a failure rate in weight loss diets of around 95\% $\%^{7,27}$.

Subjects do not only report that the diets are inefficient but also confirm the hypothesis of the rebound plus effect of diets. $50.7 \%$ of the dieters claim to have suffered this side-effect of dieting. This figure coincides with previous studies ${ }^{8,9}$. In study ${ }^{25}, 37 \%$ of the subjects put back on weight equal to or greater than the weight they had lost and one subject put back on $216 \%$ of the weight lost. These figures seem to indicate how general this effect is, and show the need to carry out a rigorous evaluation of the effects of previous diets on the person's weight in order to identify those who are most susceptible to suffering from it.

These data may have various clinical implications associated with the restrictive practices which some people carry out in order to control their weight. It would appear to be of fundamental importance for obesity control programs to underline that restrictive behavior such as skipping meals can have a 
paradoxical effect, especially in overweight women. On the other hand, eating meals four or five times a day can help the person to organize their eating habits better and prevent those severe sensations of hunger which are the usual consequence of restriction and the precursor of eating excesses.

\section{References}

1. Amigo I, Fernández C. Effects of diets and their role in weight control. Psychol Health Med J 2007; 12: 321-327.

2. Kottke TE, Clark NM, Aase LA, Brandel CL, Brekke MJ, Brekke LN, et al. Self-reported weight, weight goals, and weight control strategies of a midwestern population. Mayo Clin Proced 2002; 77: 114-121.

3. Serdula MK, Mokdad AH, Williamson DF, Galuska DA, Mendlein JM, Heath GW. Prevalence of attempting weight loss and strategies for controlling weight. JAMA 1999; 282: 1353-1358.

4. Prentice AM, Jebb SA. Obesity in Britain. Gluttony or Sloth? BMJ 1995; 311: 437-439.

5. Hensrud DD, Klein S. Extreme obesity: a new medical crisis in the United States. Mayo Clin Proced 2006; 81: S5-S10.

6. Ryttig KR, Flaten H, Rossner S. Long-term effects of a very low calorie diet (Nutrilett) in obesity treatment. Int J Eat Disord 1998; 24:185-192.

7. Sarlio-Lahteenkorva S, Rissanen A, Kaprio J. A descriptive study of weight loss maintenance: 6 and 15 year follow-up of initially overweight adults. Int J Obes Relat Metab Disord 2000; 24: 116-125.

8. Korkeila M, Rissanen A, Kaprio J, Sorensen TI, Koskenvuo M. Weight-loss attempts and risk of major weight gain: a prospective study in Finnish adults. Am J Clin Nutr 1999; 70: 965-975.

9. Kroke A, Liese AD, Schulz M, Bergmann MM, Klipstein-Grobusch K, Hoffmann K, et al. Recent weight changes and weight cycling as predictors of subsequent two year weight change in a middle-aged cohort. Int $\mathrm{J}$ Obes Relat Metab Disord 2002; 26: 403-409.

10. Ogden J. Cognitive and motivational consequence of dieting. Eur Eat Disord Rev 1995; 24: 228-241

11. Timmerman GM, Gregg EK. Dieting, perceived deprivation and preoccupation with food. West J Nurs Res 2003; 25: 405-418.
12. Herman CP, Polivy J. Restrained eating. In: Stunkard AJ, editor. Obesity. London: Saunders; 1980. p. 208-225.

13. Ogden J. The psychology of eating. Oxford: Blackwell; 2003.

14. Ogawa R, Strader AD, Clegg DJ, Sakai RR, Seeley RJ, Wood SC. Chronic food restriction and reduced dietary fat: risk factors for bouts of overeating. Physiol Behav 2005; 15: 578-585.

15. Kretschmer BD, Schelling P, Beier N, Liebscher C, Treutel S, Krüger N, et al. Modulatory role of food, feeding regime and physical exercise on body weight and insulin resisitance. Life Sci 2005; 14:1553-1573.

16. Herman CP, Polivy J. Restrain and excess in dieters and bulimics. In: Pirke KM, Plog D, Vandereycken W, editors. The Psychobiology of bulimia. Berlin: Springer-Verlag; 1988. p. 33-41.

17. Rahkonen O, Lundberg O, Lahelma E, Huuhka M. Body mass and social class: a comparison of Finland and Sweden in the 1990s. J Public Health Policy 19; 19:88-105.

18. O`Dea JA. Gender, ethnicity, culture and social class influences on childhood obesity among Australian Schoolchildren: implications for treatment, prevention and community education. Health Soc Care Community 2008; 16(3): 282-290.

19. Garner DM, Garfinkel PE. The Eating Attitudes Test: an index of the symptoms of anorexia nervosa. Psychol Med 1979; 9:273-279.

20. Castro J, Toro J, Salamero M, Guimera E. The Eating Attitudes Test: validation of the Spanish version. Evaluación Psicológica 1991; 7: 175-190.

21. Herman CP, Polivy J, Esses VM. The illusion of counterregulation. Appetite 1987; 9: 161-169.

22. Kaye WH, Welztin TE, McKee M, McConaha C, Hansen D, Hsu LK. Laboratory assessment of feeding behavior in bulimia nervosa and healthy women: methods for developing a human-feeding laboratory. Am J Clin Nutr 1992; 55: 372-380.

23. Lowe M, Foster GD, Kerzhnerman I, Swain RM, Wadden T. Restrictive dieting vs "undieting". Effects on eating regulation in obese clinic attenders. Addict Behav 2001; 26: 253-266.

24. Polivy J, Herman CP, McFarlane T. Effects of anxiety on eating: does palatability moderate distress-induced overeating in dieters? J Abnorm Psychol 1994; 103: 505-510.

25. Polivy J, Herman CP. Dietary restraint and binge eating: response to Charnock. Br J Clin Psychol 1989; 28: 341-344. 
26. Neumark-Sztainer D, Wall M, Guo J, Story M, Haines J, Eisenberg M. Obesity, disordered eating, and eating disorders in a longitudinal study of adolescents: how do dieters fare 5 years later? J Am Diet Assoc 2006; 106: 559-568.

27. Brownell KD, Rodin RJ. The dieting maelstrom: Is it possible and advisable to lose weight? Am Psychologist 1994; 49: 781-791.
Address for correspondence:

Isaac Amigo

Facultad de Psicología

Universidad de Oviedo

Plaza Feijoo s/n. 33003-Oviedo

Spain

E-mail: amigo@uniovi.es 